\title{
'|||||||||||||||||||||||||||||||||||||||||||||||||||||||||||||||||||||||.
}

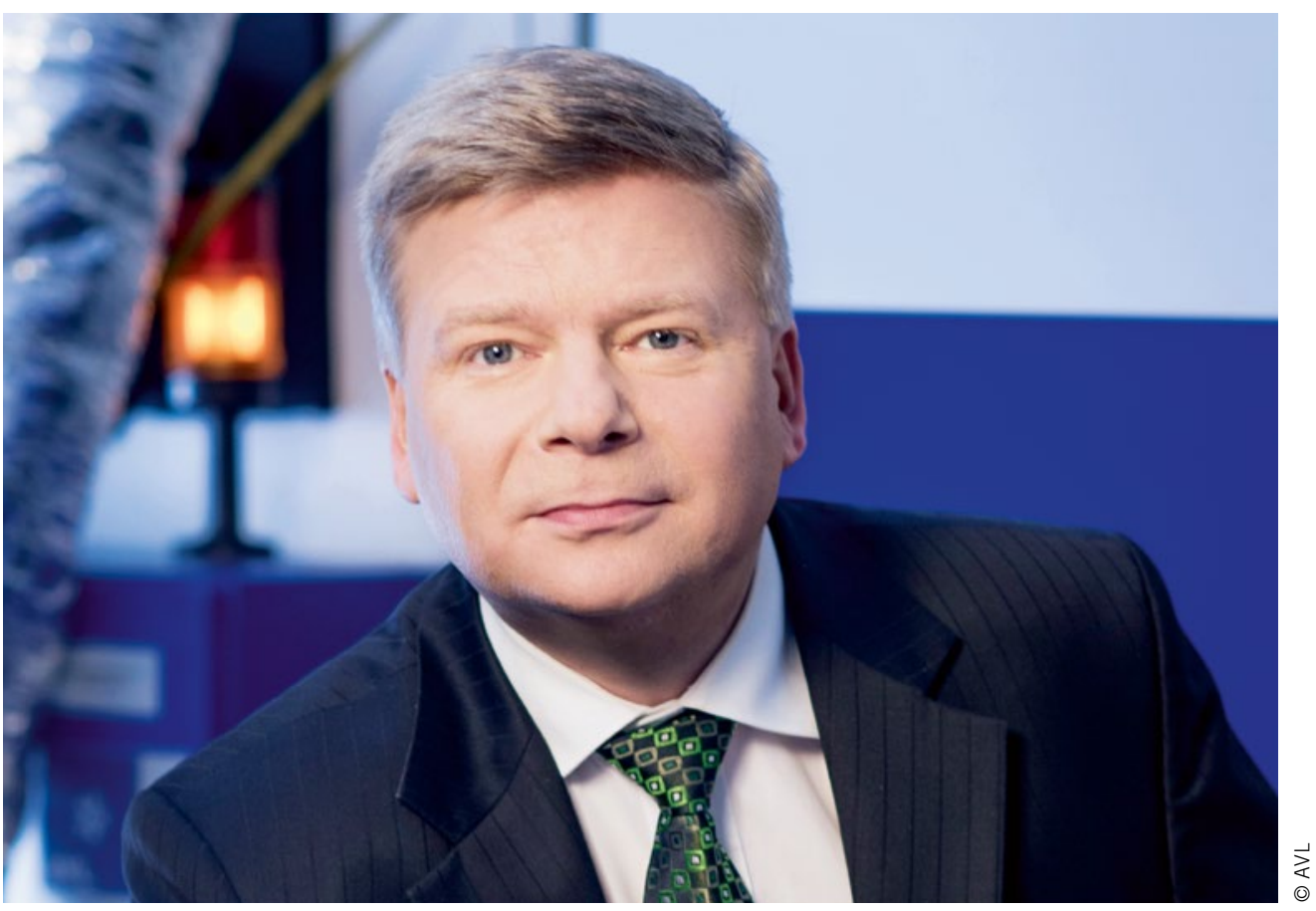

Marko Dekena

Executive Vice President

AVL List $\mathrm{GmbH}$ and

CIMAC Vice-President

Technical Programme

\section{Why System Integration?}

The CIMAC Council recently decided to establish the working Group "System Integration”. Designated Working Group 20, the group brings together all relevant stakeholders: engine developers and builders, their component suppliers, system integrators, the Classification Societies and, very importantly, engine users.

The rationale behind WG 20 System Integration is that the engine industry is employing new technologies as a valuable contribution to a cleaner environment. Diesel engines have improved immensely in their reliability, efficiency and $\mathrm{NO}_{\mathrm{x}}$ emissions. At the same time, the power density and efficiency of gas engines has improved, adding valuable performance to zero soot and sulphur-based pollution and some $20 \%$ less $\mathrm{NO}_{\mathrm{x}}$ than diesels.

But our industry is facing new, broader challenges. The most fundamental is to increase the overall efficiency of ships and other large engine applications. We can increase engine efficiency by a few percentage points but due to physical limitations, increases in overall system efficiency of 10,20 or even $30 \%$ will require an holistic approach, which takes into account the whole powertrain and focuses on comprehensive system engineering solutions.

Accordingly, the marine industry has already taken an important first step in this direction with the Energy Efficiency Design Index (EEDI). There are many types of ships, locomotives and other applications that operate on highly transient cycles with long periods at low load and idle. The aim is to operate the engine in its most efficient fuel map range by reducing engine speed, increasing average BMEP and even shutting down the engine with a start-stop system whenever possible.

In many cases this can be achieved by adding electric drive, control and storage elements. Driven by hybridisation and electrification in passenger cars and commercial vehicles, a range of components is already available, including batteries, electric motors, converters, inverters, and gears, etc. These cuttingedge technologies can be adapted to allow the large engine industry to emulate the efficiency gains in the automotive sector. Due to improvements in their functionality and reliability, the elements concerned can now be considered high quality and, indeed, in most cases they already meet the high reliability demanded in the large engine sector.

System optimisation, with the aim of high efficiency, is not only a challenge, but also a great opportunity. It paves the way for an essential improvement in fuel consumption and thus reduced $\mathrm{CO}_{2}$ emissions. It is also a key chance to significantly reduce operating costs.

These factors made it essential for CIMAC to establish Working Group 20 System Integration, so that we have a shared platform to forge consensuses, work out solutions and contribute to the safety standards necessary for the next generation of power systems using large engines. 